\title{
MAIA, Claudia; PUGA, Vera Lúcia (Org.). História das mulheres e do gênero em Minas Gerais. Florianópolis: Editora Mulheres, 2015. 552 p.
}

Lançado nas primeiras luzes de 2015 pela Editora Mulheres, História das mulheres e do gênero em Minas Gerais reúne resultados de pesquisas realizadas, seguindo uma tradição transdisciplinar, na área dos estudos sobre as mulheres e o gênero, especialmente no espaço empírico de Minas Gerais. Dessa forma, o livro muito bem organizado pelas professoras doutoras Claudia Maia e Vera Lúcia Puga, agrega estudiosos que escrevem a partir da História Social e Cultural - e se valem de fontes diversificadas, bem como contemplam diferentes momentos históricos, contudo, alguns trabalhos abrangem o campo da literatura, permeado pela História e pela Cultura. Os(as) autores(as) são, na grande maioria, professores/pesquisadores, doutores e mestres de Instituições de Ensino que participaram dos vários Encontros Regionais de História promovidos pela ANPUH-MG de forma bienal, entre 2006 e 2012 em diversas cidades mineiras, com o objetivo de debater e propagar os estudos feministas e de gênero desenvolvidos especialmente a partir de Minas. Entre elas se destacam Constância Lima Duarte e Diva de Couto Muniz que muito tem contribuído nessa linha de pesquisa no Brasil.

Vinte e dois textos estão divididos em quatro partes, conforme a abordagem temática comum. Em Transgressoras e insubmissas mineiras o próprio título já remete o(a) leitor(a) às mulheres mineiras atuantes em seu contexto social, no sentido de denunciar a opressão e a violência; mulheres que ousaram desacatar a ordem vigente e infringiram modelos femininos estabelecidos como norma. Em vários trabalhos aparecem mulheres de diversas classes, raças e épocas; são profissionais, chefes de família, abolicionistas, feministas, escritoras, prostitutas que, de uma forma ou outra, deixam a posição histórica de vítima e oprimida para exercer o poder a partir de diferentes estratégias. Diva Muniz no texto "Professoras de Minas e das Gerais": desenho inconcluso de suas memórias e histórias traça um desenho, "inconcluso, porque histórico" (p. 24) de professoras mineiras construindo sua identidade profissional, ao mesmo tempo em que reflete sobre a "invenção do magistério como profissão feminina" (p. 24). Vanda Praxedes resgata as mulheres silenciadas na história mineira que foram concubinas de padres, transgressoras de normas sociais e religiosas, que ousaram viver seus "amores proibidos" e muitas vezes constituíram e chefiaram suas próprias famílias, ou foram relegadas a um processo de apagamento de sua presença nos documentos que legitimam a existência de filhos dessas uniões ou em testamentos - "estratégia conveniente para o sacerdote e endossada pela Igreja" (p. 69). No entanto, suas memórias surgem dos silêncios desses documentos, conforme a autora coloca em "Mulheres concubinas de padres": tramas e enredos dos amores proibidos. No capítulo "Liberdade aos infelizes escravizados": mulheres, política e abolicionismo em Minas Gerais (1850-1888), Fabiana Macena descreve a atuação de abolicionistas mulheres livres ou escravas - na luta pela liberdade na sociedade mineira oitocentista. Contrapondo-se à política de exclusão e do silenciamento, própria do século XIX, mulheres livres lutaram em várias frentes abolicionistas "apesar dos limites impostos pela ordem patriarcal" (p. 83). Por outro lado, mulheres escravas também atuaram, cada qual a seu modo, em fugas, petições e recursos à justiça (quando alfabetizadas porque filhas bastardas de seus senhores) contribuindo para a "perda da legitimidade da escravidão" (p. 92). Cláudia Maia e Patrícia Lessa dos Santos nos apresentam uma intelectual feminista mineira ferrenha, Maria Lacerda de Moura, escritora, jornalista, conferencista, conhecida nacionalmente e no exterior, que "expôs a condição feminina no centro de suas reflexões críticas, posicionando-se contra o autoritarismo do Estado, da Religião e da Família" (p. 103). O texto rico em informações e bem fundamentado discorre sobre os posicionamentos da feminista acerca da família e casamento; a dupla moral sexual da sociedade burguesa que resulta na marginalização e na exploração das mulheres como prostitutas e solteironas; além da proposta visionária de liberdade para as mulheres que incluía o amor plural e a retomada e governo do seu próprio corpo. Ainda nessa parte do livro, o capítulo "Maura Lopes Cançado": transgressão e insanidade em Minas Gerais, escrito por Márcia Moreira Custódio e Alex Fabiano Correia Jardim, discute as implicações entre vida e obra a partir da análise do livro Hospício é Deus. Já em "Gênero e violência nos contos de Conceição Evaristo", Constância Lima Duarte discorre sobre como a "escrevivência" da 
autora resulta em narrativas ficcionais em que "tudo parece falso e ao mesmo tempo verdadeiro" (p. 156) e, concomitantemente, como essas narrativas "desdobram diferentes modalidades de violência de gênero" (p. 154) atravessadas pela classe e etnia. Nos dois casos são obras ficcionais que denunciam a opressão e a violência sobre as mulheres. Fechando a primeira parte do livro o texto de Varlei Couto, valendo-se do conceito de escrita de si (Michel Foucault) como estratégia política, descreve a trajetória da prostituta Márcia de Pouso Alegre, no sul de Minas. Mesmo relegada à exclusão social e silêncio, em face de uma "campanha de moralização" da cidade em 1970, sua memória e sua subjetividade podem ser resgatadas pelas correspondências deixadas por ela. A escrita de cartas das prostitutas é interpretada pelo autor como "estratégia política que permite a essas mulheres sair do anonimato, implodir as fronteiras do esquecimento para despontarem na história" (p. 177).

Três outros capítulos compõem a segunda parte do livro, que tem por título "Damas, donas do sertão". Neles despontam figuras femininas da História de Minas e do Brasil, como Joaquina do Pompéu (17521824) abordada por Gilberto Cézar de Noronha, e Dona Tiburtina de Andrade Alves (1876-1955) pesquisada por Maria de Fátima Gomes Lima do Nascimento e Filomena Luciene Cordeiro dos Reis; assim como do estudo de "estratagemas" de personagens femininos que tentam "desenredar uma tradição patriarcal" na literatura de Guimarães Rosa.

As duas "damas" históricas fazem parte da tradição oral e historiográfica do sertão mineiro e os(as) autores(as) discutem as imagens contraditórias construídas sobre essas figuras emblemáticas. Mesmo distanciadas em um século e tendo vivido em regiões diferentes do mesmo estado, se assemelham em alguns aspectos: ambas construíram imagens de meninas com personalidade forte, voluntariosas, corajosas, transgressoras da ordem estabelecida, ambas se casam e ficam viúvas, sendo que Dona Tiburtina contrai novo casamento e Joaquina assim permanece até falecer. A imagem de Joaquina do Pompéu é controversa: "mulher poderosa, rica, detentora de prestígio junto às autoridades", "amante da pátria e da monarquia", "mulher má", "Sinhá braba", "mulher truculenta, arbitrária" e perversa, "dama do sertão", etc. Toda essa caracterização negativa dá margem à reflexão sobre "as ações de uma mulher forte numa sociedade rural cristã" (p. 206), bem como sobre as lutas pela igualdade política e social que incluem sexo, classe e raça. Já a reflexão sobre a imagem de Dona Tiburtina, desenvolvida pelas autoras, é transgressora do espaço doméstico historicamente determinado para as mulheres. Por um lado, ela é descrita como uma mulher fascinante, voluntariosa, batalhadora que sustenta a família, depois de viúva, com seu ofício de costureira, por outro, criou uma imagem de "mulher sanguinária, facínora e bandida" (p. 213). O resgate de sua história remete à reflexão crítica sobre como uma mulher ocupou o espaço político e social na década de 1930, sobretudo depois do episódio que entrou para a história local como "emboscada dos bugres", e como essa "atividade serviu tanto como meio de acesso ao poder, quanto de aceitação social." (p. 218). O texto, porém, merece ser lido pela discussão sobre a memória discursiva construída sobre sua imagem, principalmente considerando os discursos jornalísticos posteriores aos eventos do período em que ela atuou social e politicamente. Telma Borges, no capítulo "Mulheres que desenredam a tradição no sertão de Guimarães Rosa": uma leitura de "A vela ao diabo" e "Desenredo", por sua vez, fecha a parte do livro que tem o sertão mineiro como palco de representações contraditórias sobre mulheres e discute a atuação de personagens femininas rosianas a contrapelo do discurso patriarcal, lembrando que suas imagens são construídas por mãos masculinas. Mesmo a primazia discursiva sendo do homem, a autora atenta para o fato de que "as personagens femininas que desfilam pelo sertão rosiano agem na contramão do que a tradição relegou como característico do comportamento da mulher" (p. 247). Na impossibilidade de representar as mulheres do sertão conforme o modelo urbano e burguês, Guimarães Rosa criou personagens femininas ativas e livres que "desenredam" uma forma escritural masculina e falocêntrica - o que Telma Borges discute habilmente.

A terceira sessão do livro agrega textos sobre "Saberes e fazeres femininos", entre os quais Lúcia Helena Costa descreve as práticas de quatro parteiras tradicionais de Minas que, gradativamente, viram seu ofício sendo desqualificado e desautorizado na medida em que a medicina avançava e se instalava. Cairo Katrib e Fernanda Naves resgatam a memória das mulheres congadeiras de Ituiutaba-MG, que atuam como chefes de família, avós, mães e organizam os festejos em louvor a São Benedito - dessa forma, são guardiãs da tradição e da memória cultural de grupos negros. Os dois textos seguintes tratam da invisibilidade, do desprestígio das tarefas normalmente executadas por mulheres e concebidas, historicamente, como "fazeres de mulheres". Monica Abdala se vale do conceito de gênero para refletir sobre a relação mulheres e produção de comida no ambiente da cozinha mineira ao longo do século XIX e século XX, enfatizando todas as mudanças nos hábitos alimentares. Mas conclui que, mesmo com a maior participação masculina na cozinha, a "obrigação" com o trabalho doméstico, naturalizada, continua sendo da mulher mesmo no início do século XXI. Já Maria Andréa Carmo, no seu estudo sobre a crescente visibilidade da atuação das trabalhadoras rurais no triângulo mineiro, enfatiza que essa participação feminina na dinâmica produtiva ainda "não aparece em números e dados econômicos por conveniência e 
manutenção das estruturas de poder em uma sociedade patriarcal" (p. 342), bem como reforça a necessidade de rever os preconceitos que essas trabalhadoras ainda sofrem. Também de invisibilidade da atuação feminina fala o texto de João Augusto dos Santos, ao narrar a memória individual de um trabalho coletivo de mulheres que "foram responsáveis pela educação, assistência social, ornamentação dos templos, condução artística das liturgias, visitações nos lares" (p. 365), entre outros afazeres que contribuíram para o estabelecimento do Protestantismo em Montes Claros - MG, no entanto foram raramente mencionadas nas narrativas oficiais.

Leila Almeida narra histórias de vida de mulheres que interromperam seus estudos no período regular, normalmente por necessidade financeira, pela maternidade precoce, ou por razões de violência psicológica e comenta o significado do retorno ao estudo para vida dessas mulheres depois de adultas.

Finalizando a terceira parte, Maria Clara Machado e Paulo Moreira da Silva narram o processo de expropriação que envolve a família dos Amaros de Paracatu, não somente de suas terras mas também de suas identidades e da memória afrodescendente. Na luta política árdua estabelecida, os autores reconhecem a importância dos saberes da matriarca negra Ignês Pereira Guimarães (1906-2005), "que possuía vivacidade de espírito, cheia de manhas e astúcias, e que soube negociar e enfrentar conflitos[...]" (p. 416).

A última sessão reúne pesquisas que em muito contribuem para o estudo sobre as instituições como "Casamento e maternidade", explicadas biológica e culturalmente como destino natural para as mulheres. Dayse Santos procede uma minuciosa análise crítica de documentos jurídicos e eclesiásticos sobre possibilidades de dissolução de vínculos matrimoniais desde o século XIX no Brasil; Florisvaldo Ribeiro Junior analisa construções representativas da participação de mulheres, durante os primeiros anos da república brasileira, nos modos como se estabeleceu a ordem moderna que reitera "o espaço doméstico como domínio do feminino e a reprodução sexuada como função natural e cívica de toda mulher brasileira" (p. 483). Discursos moralizantes, perpassados por elementos de higienização da sociedade foram disseminados por jornais do Triângulo Mineiro em nome da modernização da sociedade, os quais "atribuem às mulheres um protagonismo que, contraditoriamente, tenta emudecê-las, moldando-as e confinando-as a espaços e papéis sociais subalternos e incompletos" (p. 501). Com o olhar para a maternidade e o casamento de mulheres adolescentes vivendo em Minas Gerais um século depois, Carla Giuliani percorre a história cultural para compreender certa circularidade no papel da maternidade na vida das mulheres, ou seja, para compreender como "as pessoas resistem e reescrevem novos juízos de valores ou recriam as tradições culturais" (p. 523).

Vera Puga fecha o livro, voltando sua atenção para educação feminina, ou melhor, para a formação dos sujeitos femininos e masculinos dentro das escolas direcionadas para sexos específicos, confessionais, profissionais ou de formação acadêmica ao longo do século $\mathrm{XX}$. O texto merece ser lido principalmente pelo alerta para uma entristecedora notícia sobre o ressurgimento de escolas para meninas em Uberlândia - MG, semelhantes às escolas domésticas da primeira metade do século $\mathrm{XX}$ que preparavam as meninas e moças para atividades do lar e de etiqueta à mesa. Denominadas como "Escolas de Princesas", elas constituem uma "tentativa de retorno às desigualdades" (p. 536) entre mulheres e homens ensinadas desde a infância. $\mathrm{O}$ grande número de alunas que essa escola já tem atendido e a repercussão do seu sucesso na mídia é preocupante, pois evidencia um retrocesso nas lutas feministas do último século, no sentido de devolver a mulher ao espaço doméstico, atribuir-lhe apenas as funções de educação dos filhos e cuidados da casa e do marido ou companheiro, bem como submetê-la novamente ao domínio e dependência do homem.

No conjunto, todos esses ensaios contribuem não só para a história das mulheres mineiras, mas também para a história das mulheres brasileiras silenciadas por questões de gênero durante séculos. As análises críticas de testemunhos, correspondências, documentos, arquivos, obras literárias entre outros, permitem ao leitor ampliar a sua visão sobre um passado esquecido, sobre sujeitos femininos invisibilizados politicamente, sobre exercícios de poder feminino não valorizados pela história oficial, assim como permitem refletir sobre a importância da continuidade dos estudos de Gênero, estudos feministas e de movimentos sociais em favor dos excluídos da História oficial.

RISOLETE MARIA HELLMANN Universidade Federal de Santa Catarina 